LBNL-51751

SCMAG-794

\title{
The Cryogenic Refrigeration System for MICE
}

\author{
Michael A. Green \\ Lawrence Berkeley National Laboratory
}

The proposed cryogenic cooling system for MICE uses a single liquid helium refrigerator to cool the superconducting magnets, the liquid hydrogen absorbers, and the scintillating fiber detectors. It is proposed that the helium refrigerator cold box deliver two-phase helium at $4.4 \mathrm{~K}$ at the saturated liquid condition and $14 \mathrm{~K}$ helium at a pressure of 14 to 18 bars. The $4.4 \mathrm{~K}$ helium will be used to cool the seven superconducting magnet assemblies in the MICE magnet string and the fiber light detectors. The $14 \mathrm{~K}$ helium will be used to cool the liquid hydrogen absorbers, the magnet shields, and the gas cooled electrical leads that go from about $50 \mathrm{~K}$ to room temperature. Helium returns to the refrigerator from the magnet string and detector box at $4.3 \mathrm{~K}$. The helium gas from the absorbers returns to the refrigerator as a gas at $18 \mathrm{~K}$ or lower. The helium that will be used to cool the magnet shields and leads will by pass the refrigerator cold box and return to the refrigerator compressor at about $293 \mathrm{~K}$.

\section{Forced Two-phase Helium Cooling for the Magnets}

It is proposed that the superconducting coils for the MICE magnets be cooled by conduction from the magnet coil support structure. A number of large detector magnets are cooled this way. The magnet support structure will be cooled by two-phase helium in cooling tubes that have an ID about $10 \mathrm{~mm}$.

It is proposed that the solenoid magnets be cooled in series using a single cooling circuit that goes from the refrigerator through the magnets and back to the refrigerator. (See Figure 1.) The volume of liquid helium in the solenoids will be very low (of the order of a few liters). The advantages of twophase helium cooling of the magnets are as follows: 1) The cool down of the magnet string is straightforward and well controlled. To first order, the magnet cool down rate is proportional to the magnet mass, proportional to the temperature difference between the flow circuit inlet and the outlet, and inversely proportional to the mass flow through the circuit. 2) The overall mass of a tubular cooled magnet and its cryostat is less than the mass of a magnet with helium bath cooling. 3) The amount of helium in contact with the magnet coil during a quench is limited to the amount of helium in the cooling tube. The safety hazard of liquid helium in tubes during a loss of vacuum or a magnet quench is small compared to a bath cooled cryostat. Tubes always have a higher pressure rating than a cryostat helium vessel. In general, tubes are not covered by the pressure vessel code; the helium vessel in a bath cryostat usually is covered by the pressure vessel code. 4) Helium services to the superconducting magnets can come into the cryostat from any direction. In other words, the helium services and leads do not have to come out of the top of the cryostat. The gas cooled electrical leads can be operated at any orientation including having the cold end up and the warm end down. 


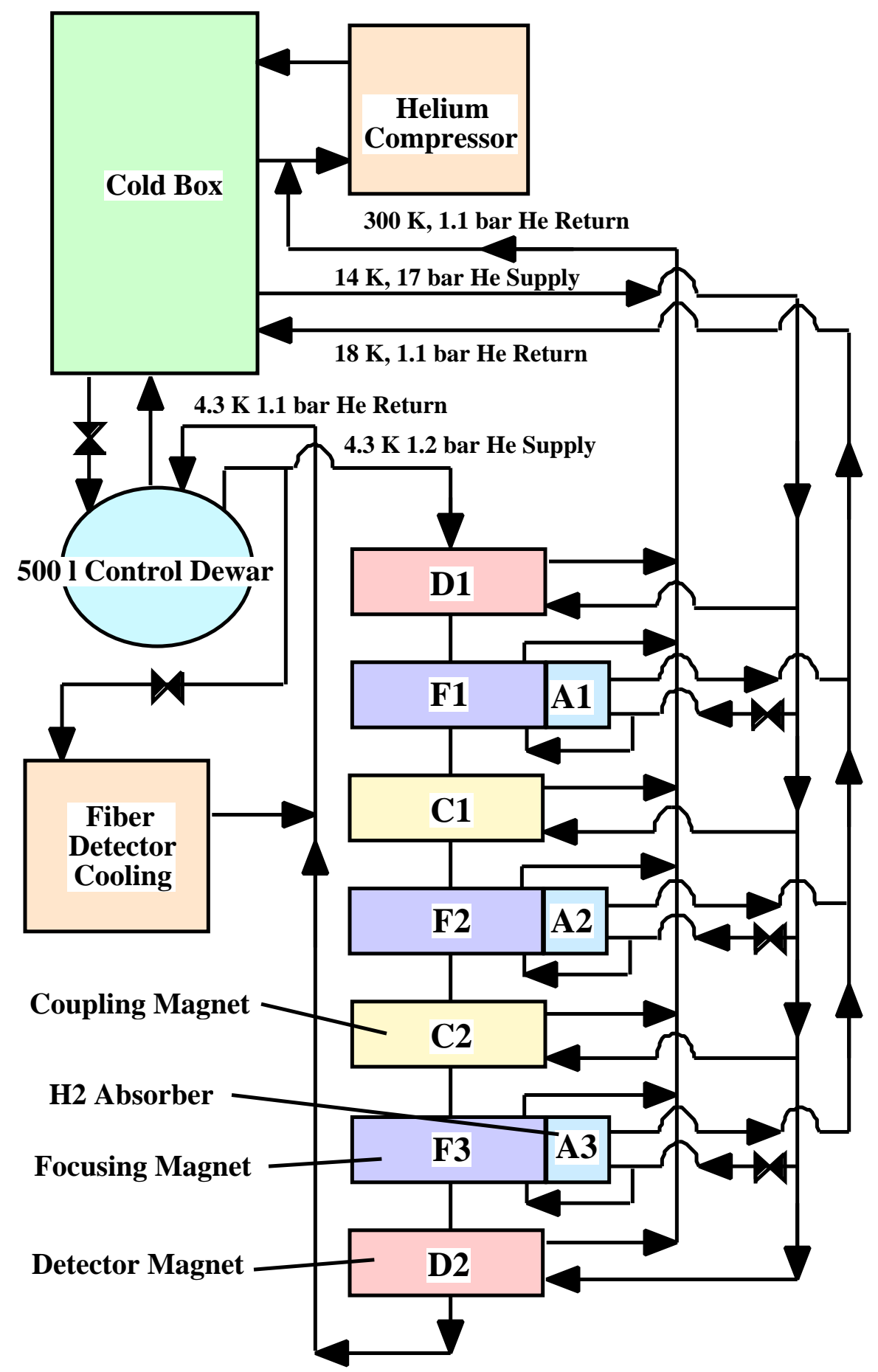

Figure 1. A Simplified Schematic Diagram of the Helium Cryogenic Cooling System for MICE. Note: The boxes labeled D1 and D2 are detector magnets; the boxes labeled F1, F2 and F3 are focusing magnets; and the boxes labeled C1 and C2 are the coupling solenoids. The absorbers A1, A2 and A3 are shown attached to the focusing magnets. It is assumed that a focusing magnet is in the same cryostat vacuum vessel as the absorber. The physical connection between the absorber and the focusing coil pair is assumed to be through a low thermal conductivity support that limits heat transfer from $18 \mathrm{~K}$ to $4 \mathrm{~K}$. 


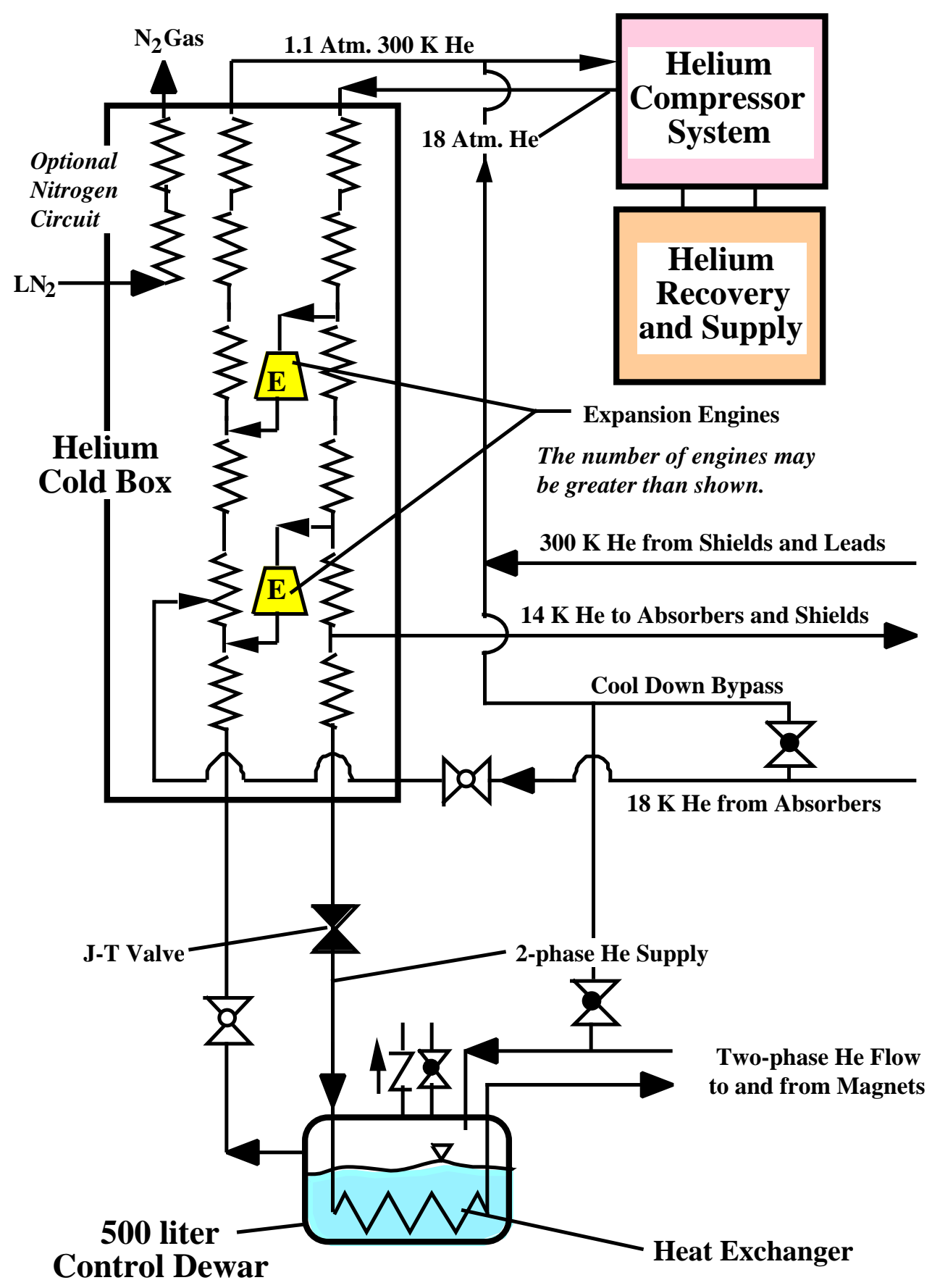

Figure 2. A Schematic Representation of the Refrigerator Cold, the Refrigerator Compressors and the Two-phase Cooling Control Dewar. The control dewar and its heat exchanger are key elements for successful two-phase cooling of one or more superconducting magnets. Most of the liquid helium in the cooling circuit is in the control dewar. Note: the refrigerator cold box is shown with two expansion engines. There could me more engines, but typical 100 to $200 \mathrm{~W}$ refrigerators have two engines as shown. The J-T valve could be replaced by a cold expander, which will increase the cooling of the refrigerator.

The diagram above shows the cool down bypasses for the refrigerator, magnets, and absorbers. 


\section{Cooling for the Magnets and the Liquid Hydrogen Absorbers}

Figure 1 shows how the superconducting magnets and the absorbers are cooled. The superconducting magnets are shown as being cooled in series. The hydrogen absorbers are cooled in parallel. The cooling for the magnet shields and leads off of the $14 \mathrm{~K}$ circuit is shown as being in parallel with the absorber cooling. Figure 1 shows the primary control valves for the cooling system. (They are shown as darkened double triangles.) The control valve between the refrigerator and the control dewar is the J-T valve that produces the two-phase helium needed to cool the magnet string. The control valves that go into each of the absorbers will control the helium flow depending on the temperature of the helium stream leaving the absorber. It should be noted that the temperature of the helium entering the control valve is shown as $14 \mathrm{~K}$. This temperature may have to be higher than $14 \mathrm{~K}$ because expansion through the control valve will cause cooling of the helium entering the absorber. The helium gas entering the absorber must be above $13 \mathrm{~K}$, which is the freezing temperature for liquid hydrogen in the absorber.

\section{The Control Dewar for the Two-phase Helium Distribution System}

Figure 2 shows the refrigerator cold box, the compressors and the liquid helium control dewar. The use of a control dewar with a heat exchanger (as shown in Figure 2) is essential for reliable operation of a two-phase helium cooling circuit. The role of the control dewar and its heat exchanger is to sub-cool the helium entering the magnet string. The advantages of this approach are: 1) The liquid in the control dewar is colder than the two-phase helium mixture coming off of the J-T valve. The heat flow from the two-phase helium to the helium bath in the dewar condenses the helium in the cooling tube and drops its temperature below the saturation temperature for the helium in the heat exchanger tube. The average density of the helium in the tube increases over a factor of three and as a result, the pressure drop in the flow circuit from magnet to magnet is reduced over a factor of two. 2) The control dewar and its heat exchanger has the effect of damping out the pressure oscillations that often occur in two phase flow circuits. This feature extend even to the so called garden oscillation caused by a twophase mixture going up and down through many turns of a tube. Simply put, two-phase flow circuits that do not work without a control dewar and its heat exchanger will usually work when a control dewar is used. In a well-designed two-phase flow cooling system, the control dewar eliminates or greatly reduces pressure oscillations often seen in flow circuits. 3) The control dewar acts as a buffer vessel that can provided additional cooling at times when the heat load exceeds the capacity of the available refrigeration. Up to 1.5 times the rated capacity of the refrigeration capacity can be delivered to the load as long as there is liquid helium in the control dewar. If one does not allow quench gas to vent back through the control dewar, one can use the liquid helium in the control dewar to provide added cooling for the magnets when they are being re-cooled after a quench.

It is proposed that the control dewar be a standard wide neck 500-liter dewar built by a commercial vendor. The neck inside diameter should be at least $100 \mathrm{~mm}$. A 100-mm diameter neck will allow one to install a heat exchanger fabricated from 12.7-mm OD tube. When installed, the heat exchanger would 
sit in the lower one third of the dewar liquid space. The use of a standard 500-liter storage dewar means that the control dewar can be relatively inexpensive and it can be certified as being safe.

Figure 2 also shows the by-pass that is used when the magnets and the absorbers are being cooled down from room temperature. The by-pass that is shown completely bypasses the cold box. An alternative to this is a by-pass is one that goes into the cold box and allows the return gas to enter the return side of the refrigerator heat exchanger at various points as the return gas is cooled to allow it to enter the refrigerator at that point. The use of by-pass as shown in Figure 2 is a simple way of cooling down any cryogenic system from room temperature to its operating temperature using a refrigerator.

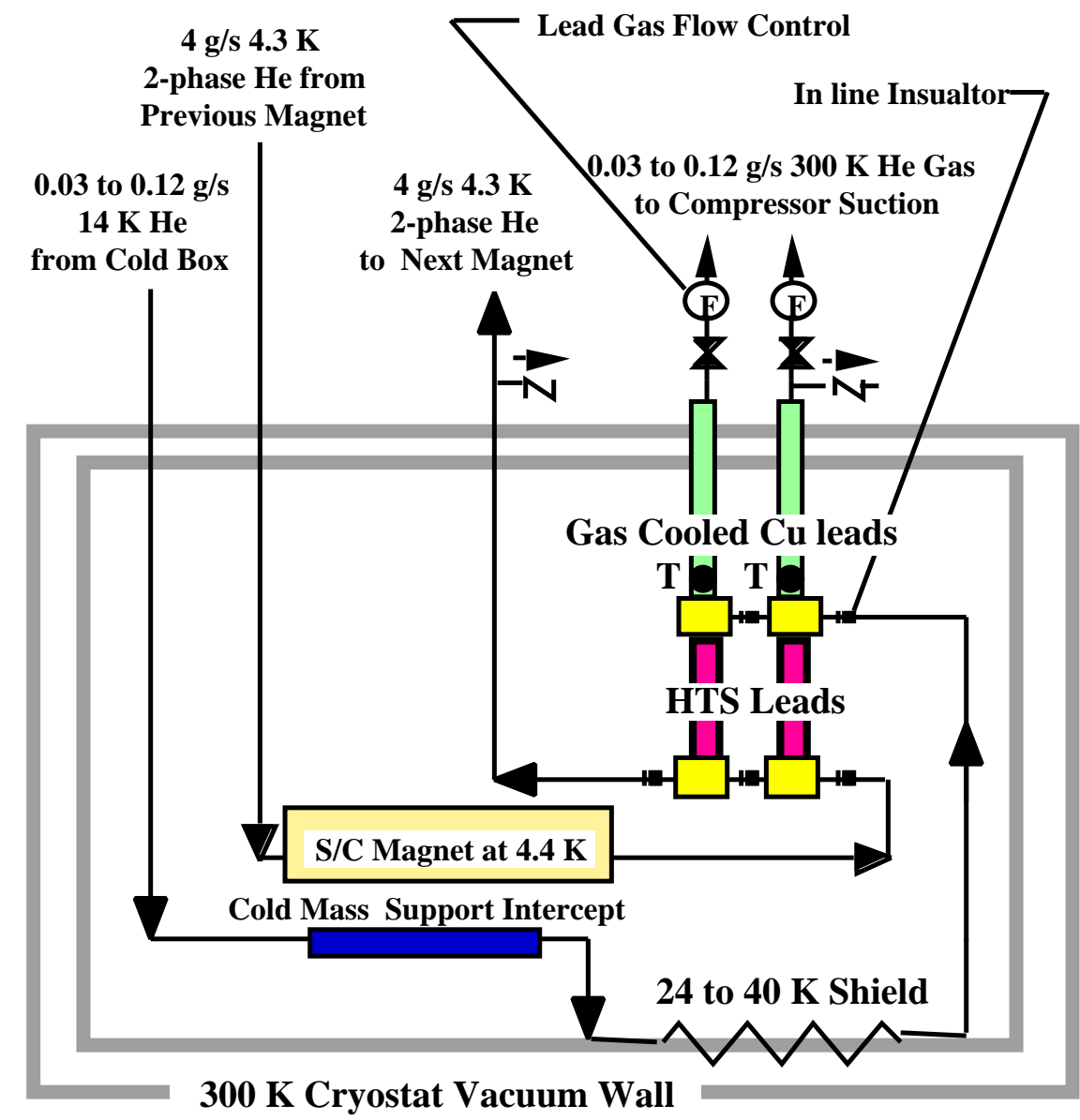

Figure 3. A Schematic Representation of the Flow of Two-phase Helium and $14 \mathrm{~K}$ helium in a Coupling Magnet or Detector Magnet Cryostat. Note: the lead current for the coupling magnet is assumed to be $1000 \mathrm{~A}$. The lead current for the detector solenoids is 200 to 250 A. It should be noted that the detector solenoid has at least four pairs of leads.

Figure 3 shows a schematic representation of the cooling of a coupling magnet or a detector magnet. The magnet coil is cooled using two-phase helium in a pipe attached to the coil support structure. Before the two-phase helium leaves the magnet cryostat, the lower part of the high temperature superconductor leads (HTS) must cooled by the two-phase helium in order to intercept any 
heat coming down the HTS leads. The use of HTS leads reduces the heat flow into the $4.4 \mathrm{~K}$ region. If conventional gas cooled leads were used, helium needed for lead cooling would be drawn off the twophase cooling circuit. In the coupling magnet, 0.1 to $0.12-\mathrm{g} \mathrm{s}^{-1}$ would be drawn off and returned to the compressor at room temperature. As a result, the equivalent $4.4 \mathrm{~K}$ refrigeration needed for cooling a single coupling magnet must be increased by about $12 \mathrm{~W}$. The use of HTS leads on the detector magnets will save the equivalent of about $12 \mathrm{~W}$ of refrigeration at $4.4 \mathrm{~K}$ for each magnet.

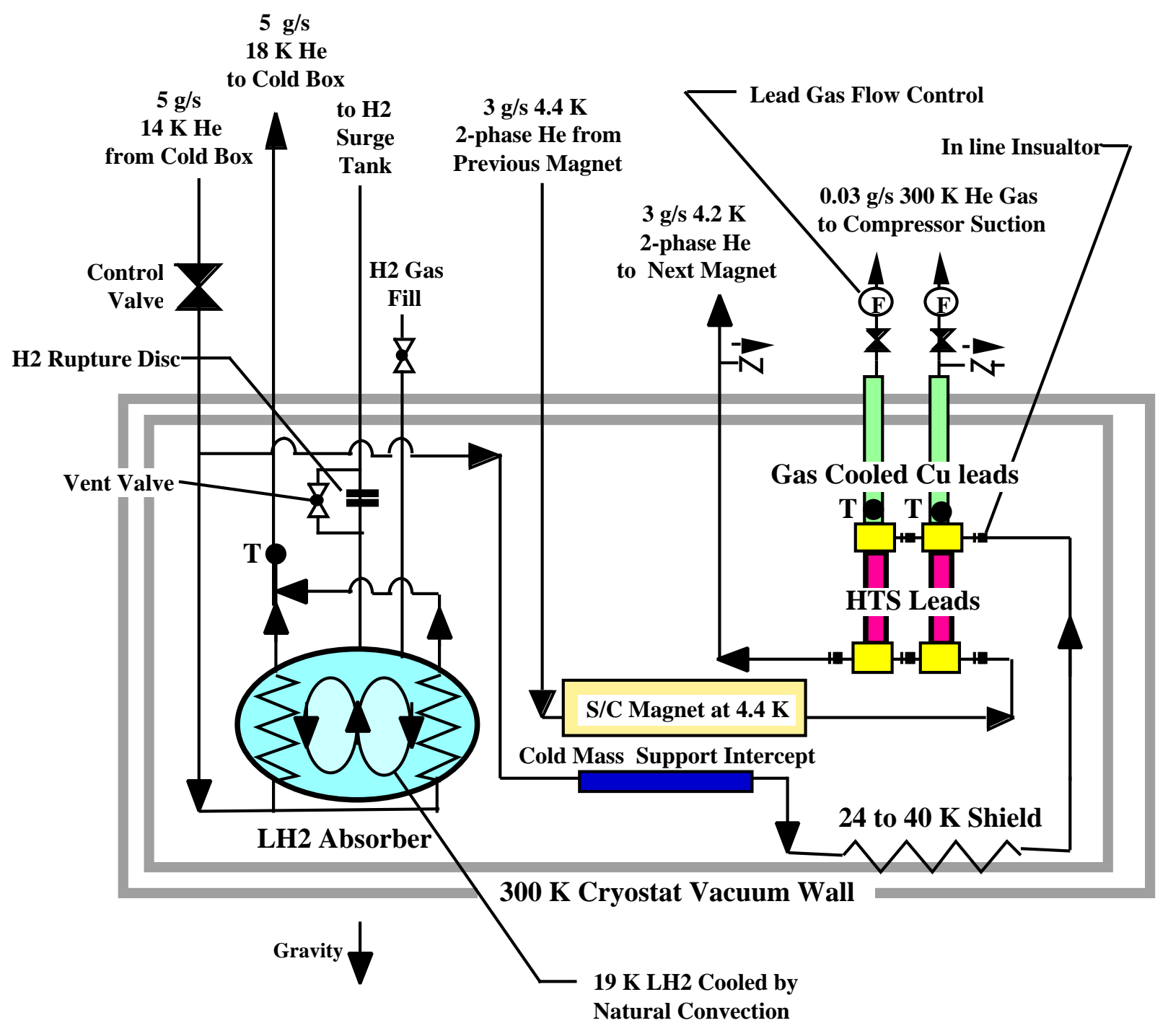

Figure 4. A Schematic Representation of the Cooling of the Focusing Magnet and the Hydrogen Absorber The helium circulating in the walls of the absorber is shown as a heat exchanger that has the helium going up. The hydrogen circulates so that it passes down the absorber walls as it is cooled. The heated hydrogen rises up the center region of the absorber while the cooled hydrogen goes down along the absorber wall. The hydrogen enters the absorber as a gas. It is condensed on the absorber wall to form liquid hydrogen. There should be no need for a liquid fill of the absorber. When the hydrogen is returned to the surge thank, it can return through the same line that is used to fill the absorber. 


\section{Cooling of the Liquid Hydrogen Absorber}

Figure 4 shows a schematic view of how the liquid hydrogen absorber and the focusing solenoid can be cooled from the MICE cryogenic system. It is assumed that the hydrogen in the absorber is cooled by free convection to the walls of the absorber (a separate heat exchanger may be better) that is cooled by helium from the refrigerator that enters the absorber at $14 \mathrm{~K}$. Hydrogen that is in the absorber moves upward because it is less dense. The hydrogen moving upward is replaced by cooler more dense hydrogen that is moving down the walls of the absorber body (or a separate heat exchanger). The absorber body walls forms a counter-flow heat exchanger where heat is transferred from the helium flowing in tubes attached to the wall to the liquid hydrogen flowing down the walls of the absorber.

The helium that enters the absorber at $14 \mathrm{~K}$ must be split into two streams that flow from the bottom of the absorber to the top of the absorber. If the helium enters the absorber at $14 \mathrm{~K}$ and leaves the absorber at $18 \mathrm{~K}$ about $0.05-\mathrm{g} \mathrm{s}^{-1}$ of helium flow is needed for each watt of heat removed from the liquid hydrogen. The required helium mass flow in inversely proportional to the temperature difference between the helium inlet and out let. For an absorber with $80 \mathrm{~W}$ of heating and helium gas entering at $14 \mathrm{~K}$ and exiting at $18 \mathrm{~K}$, the helium flow through the absorber body is about $4 \mathrm{~g} \mathrm{~s}^{-1}$. Since the liquid hydrogen in the absorber must always be kept sub-cooled, in order to avoid boiling, the maximum allowable absorber temperature is 20 to $22 \mathrm{~K}$ depending on maximum allowable pressure on the absorber windows. The temperature difference that drives the free convection and the heat transfer from the liquid hydrogen to the helium from the refrigerator can be no more than $8 \mathrm{~K}$. In reality, this temperature difference is less than half of that value. The design of the free convection flow circuit and the heat exchanger that exchanges the heat from the hydrogen in the absorber to the helium flowing through the absorber is very important. This will be the topic of a different design note.

The cooling circuit shown in Figure 4 reflects the need for counter flow heat exchanger from the hydrogen in the absorber to the helium flowing through tubes in the body of the absorber. Figure 4 shows that the helium must enter the absorber body from the bottom; it must exit the absorber body from the top. The hydrogen that is in the absorber is just liquid in a flask. Liquid hydrogen does not have to be transferred to the absorber. The liquid can be condensed from hydrogen gas that enters the absorber through a fill tube. The hydrogen can be drained from absorber rapidly by opening a valve that allows the liquid hydrogen in the absorber to expand into an evacuated tank. This type of safety system has been used for hydrogen bubble chambers with large volumes of liquid hydrogen. A hydrogen absorber with 380-mm diameter windows would have a total liquid hydrogen volume of about 38 liters. The volume of the evacuated tank needed for the hydrogen from three absorbers would be about $100 \mathrm{~m}^{3}$.

The heat leak from the absorber body to the focusing solenoid depends on how the absorber body is supported. If one supports the absorber from room temperature the heat leak to the magnet is small. If one supports the absorber body directly to the magnet coil support structure, the heat leak will be small even when on considers the possible de-centering forces that might occur on the absorber during a focusing magnet quench. From $22 \mathrm{~K}$ to $4 \mathrm{~K}$, the thermal conductivity integral of G-10 is about $2 \mathrm{~W} \mathrm{~m}^{-1}$. Large magnetic forces (say 100 tons) can be carried with heat rates from the absorber body to the magnet support structure that are less than $0.2 \mathrm{~W}$ to the $4 \mathrm{~K}$ region. 
If liquid helium were used in the absorber instead of liquid hydrogen, the absorber body would be cooled using two phase helium at $4.4 \mathrm{~K}$. The absorber would be filled with helium at 2 bar (just below the critical pressure for helium). The driving temperature difference for natural convection cooling would be about $0.6 \mathrm{~K}$ instead of the 5 to $6 \mathrm{~K}$ for the absorber when it is filled with hydrogen. The maximum allowable heat flow into the absorber fluid drops from $150 \mathrm{~W}$ to about $15 \mathrm{~W}$. The heat conducted into the absorber body from the outer windows and the connection to room temperature will be the same as it is for the hydrogen absorber (about $33 \mathrm{~W}$ per absorber). This heat must be transferred to the two-phase helium directly without passing into the absorber fluid. The maximum cooling to three absorbers that operate with liquid helium instead of liquid hydrogen is about $140 \mathrm{~W}$ at $4.4 \mathrm{~K}$. This heat load is about half of the heat flow into the $14 \mathrm{~K}$ helium used to cool the hydrogen absorber.

\section{Cooling the Scintillating Fiber Detectors}

The detectors that detect the photons from the scintillating fibers that are in the NICE detectors operate at a temperature between 5.0 and $5.9 \mathrm{~K}$. The D0 experiment at Fermilab used similar detectors, which are cooled by a liquid helium bath. A liquid nitrogen cooling stage intercepts heat that comes down the fibers. The maximum number of channels for MICE is about half the number of channels in the D0 experiment. The D0 experiment at Fermilab uses 200 to $300 \mathrm{~W}$ of cooling at $4.4 \mathrm{~K}$ plus about 2 $\mathrm{kW}$ of cooling at liquid nitrogen temperature. The maximum heat load to the MICE detector cooling is about $150 \mathrm{~W}$ at $4.4 \mathrm{~K}$ plus $1000 \mathrm{~W}$ at $80 \mathrm{~K}$.

The actual heat load to the MICE scintillating fiber detectors could be much lower than to $150 \mathrm{~W}$ quoted in the previous paragraph. At least two factors will influence the heat load. The first is the number of scintillating fiber channels needed to overcome the background noise due to the dark currents and $\mathrm{x}$-rays from the RF cavities. The number of channels entering the detector is also influenced by how these channels are multiplexed before entering the scintillating fiber light detector. There is at least one scenario that suggests that the number of fiber channel that need to be cooled might be one or two percent of the number of channels entering the D0 scintillating fiber light detector. In this scenario, one or two cryocoolers could produce cooling at $5.5 \mathrm{~K}$ and $60 \mathrm{~K}$ to cool the detectors and intercept heat coming down the fibers. If a TPG is used as a MICE detector, there should be no need for cryogenic refrigeration.

\section{Calculated Heat Loads and the Size of the Helium Refrigerator}

Table 1 shows the worst case projected heat loads at $4.4 \mathrm{~K}$, the heat loads at 14 to $18 \mathrm{~K}$ and the 14 $\mathrm{K}$ helium mass flow needed to cool the magnet shields and the upper gas-cooled electrical leads. The table also includes the liquid nitrogen flow needed to intercept heat flowing down the scintillating fibers into the scintillating fiber light detector. From the calculated heat loads, one can determine the equivalent refrigeration at $4.4 \mathrm{~K}$ needed to cool MICE. This permits one to determine the size of the refrigerator needed for MICE and the input power and water cooling that is needed to provide the refrigeration for MICE. 
Table 1. Heat Loads and Refrigeration Requirements for MICE

Parameter

$\begin{array}{ccc}\text { Heat Load } & \text { Heat Load } & \text { Lead Flow } \\ \text { at } 4.4 \mathrm{~K}(\mathrm{~W}) & \text { at } 14 \mathrm{~K}(\mathrm{~W}) & \text { at } 14 \mathrm{~K}\left(\mathrm{~g} \mathrm{~s}^{-1}\right)\end{array}$

Seven Super conducting Magnets

Two Coupler Magnets

30.3

0.20

Three Focusing Magnets

5.2

21.9

0.18

Two Detector Magnets

2.8

13.8

0.24

Liquid Helium Transfer Line (includes. Bayonets)

27.4

Total Heat Load and Mass Flow

66.6

0.66

Three Liquid Hydrogen Absorbers

Radiation Load to Windows

39

Conduction Heat Load to the Absorber Body

60

Beam and Dark Current Heating Allowance

60

Convection Heaters

90

Helium Transfer Lines (includes Bayonets)

Heat Load to the $14 \mathrm{~K}$ Helium Gas

290

Scintillating Fiber Detectors at $4.4 \mathrm{~K}$

150.0

Liquid Nitrogen Cooling for the Scintillating Fiber Detectors $=1000 \mathrm{~W} @ 80 \mathrm{~K}=\sim 20 \mathrm{liter} / \mathrm{hr}$ of $\mathrm{LN}_{2}$. Equivalent Refrigeration at $4.4 \mathrm{~K}$ and Refrigerator Input Power

Equivalent 4.4 K Refrigeration Needed

Design Size of the Equivalent 4.4 K Refrigerator

Total Installed Input Power for the Compressors
$307 \mathrm{~W}$

$\sim 420 \mathrm{~W}$

$\sim 295 \mathrm{~kW}$

The calculated refrigeration load for MICE is about $190 \mathrm{~W}$ at $4.4 \mathrm{~K}$ (including the heat load to the scintillating fiber light detectors), plus $290 \mathrm{~W}$ from 14 to $18 \mathrm{~K}$ plus 0.66 grams per second of helium gas taken from the cold box at $14 \mathrm{~K}$ and returned to the compressor intake at $293 \mathrm{~K}$. This refrigeration is equivalent to about $307 \mathrm{~W}$ at $4.4 \mathrm{~K}$. In order to allow for errors and additional margin, a $420 \mathrm{~W} 4.4 \mathrm{~K}$ helium refrigerator should be installed. This means that the installed power needed to power the MICE refrigeration system should be about $300 \mathrm{~kW}$.

If liquid helium is used in the absorbers instead of liquid hydrogen, the required helium refrigeration plant capacity will go up from $307 \mathrm{~W}$ to about $360 \mathrm{~W}$. One may want to increase the size of the cold box from $420 \mathrm{~W}$ at $4.4 \mathrm{~K}$ to about $450 \mathrm{~W}$ at $4.4 \mathrm{~K}$ to allow one to operate the MICE absorbers with liquid helium in place of liquid hydrogen. Since most of the power that goes into the compressor is extracted as heat, the required cooling capacity for the compressors will equal the installed power for the refrigeration system. 


\section{Cost Estimate for the MICE Refrigeration}

The MICE refrigerator is sized between 420 and $450 \mathrm{~W}$ at $4.5 \mathrm{~K}$. The costs for a number of different refrigerators is given in Figure 5 below [1]. Using the cost equation given in Figure 5, one comes up with an estimated MICE refrigerator cost of about 1.1-M\$. This cost includes, the refrigerator cold box, the compressor station, the helium recovery system, and the refrigerator control system. An addition $450 \mathrm{k} \$$ must be spent to provide the transfer lines and control cryostat for the experiment.

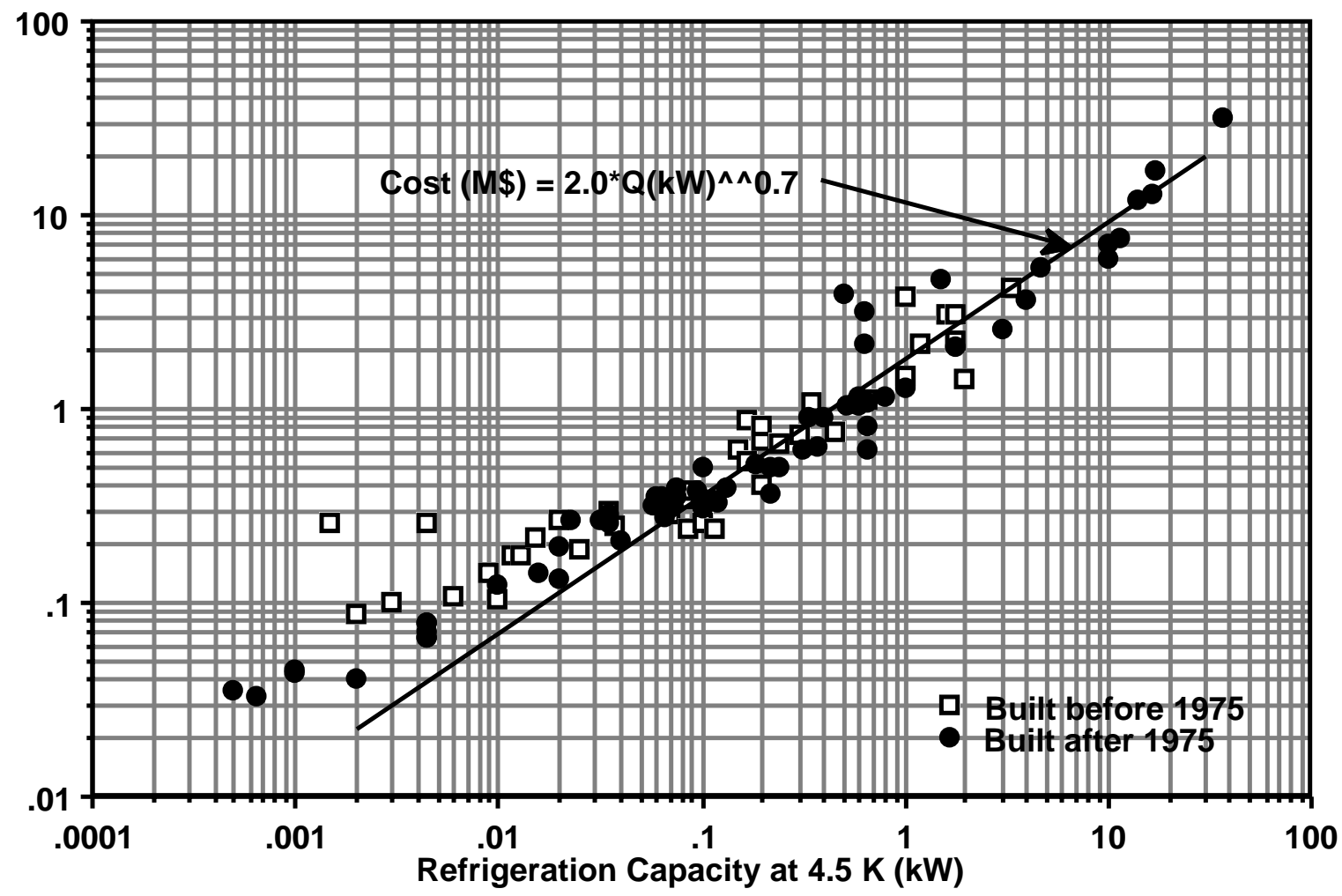

The Cost of a Variety of 4.5 K Helium Refrigerators Given in 1997 dollars as a Function of Refrigerator Size.

To covert to 2002 dollars, multiply the cost obtained from the chart by 1.18 .

\section{Acknowledgements}

This work was supported by the Office of Science, United States Department of Energy under DOE contract number DE-AC03-76SF00098

\section{References}

[1] M. A. Green and R Burns, "An Update on Estimating the Cost of Cryogenic Refrigeration," Advances in Cryogenic Engineering 43, p 1661, Plenum Press, (1997) 


\section{DISCLAIMER}

This document was prepared as an account of work sponsored by the United States Government.

While this document is believed to contain correct information, neither the United States

Government nor any agency thereof, nor The Regents of the University of California, nor any of their employees, makes any warranty, express or implied, or assumes any legal responsibility for the accuracy, completeness, or usefulness of any information, apparatus, product, or process disclosed, or represents that its use would not infringe privately owned rights. Reference herein to any specific commercial product, process, or service by its trade name, trademark, manufacturer, or otherwise, does not necessarily constitute or imply its endorsement, recommendation, or favoring by the United States Government or any agency thereof, or The Regents of the University of California. The views and opinions of authors expressed herein do not necessarily state or reflect those of the United States Government or any agency thereof, or The Regents of the University of California.

Ernest Orlando Lawrence Berkeley National Laboratory is an equal opportunity employer. 